Research Article

\title{
A Novel Approach to Fall Risk Reduction: Combining Education and Therapeutic Yoga
}

Em V. Adams ${ }^{1,}{ }^{*}$, Marieke Van Puymbroeck ${ }^{2}$, Heather S. Torphy ${ }^{2}$, Brian C. Helsel ${ }^{3}$, Karen A. Kemper ${ }^{3}$, Cheryl Dye ${ }^{4}$, Arlene A. Schmid ${ }^{5}$

1. Department of Health Sciences, Lehman College, Bronx, NY, 10468, USA; E-Mail: emilie.adams@lehman.cuny.edu

2. Department of Parks, Recreation and Tourism Studies, Recreational Therapy Program, Clemson University, Clemson, SC, 29631, USA; E-Mails: mvp@clemson.edu; htorphy@clemson.edu

3. Department of Public Health Sciences, Clemson University, Clemson, SC, USA; E-Mails: bhelsel@clemson.edu; kkaren@clemson.edu

4. Institute for Engaged Aging, Clemson University, 2037 Barre Hall, Clemson, SC, USA; E-Mail: tcheryl@clemson.edu

5. Department of Occupational Therapy, Colorado State University, Fort Collins, CO, USA; E-Mail: arlene.schmid@colostate.edu

* Correspondence: Em V. Adams; E-Mail: emilie.adams@lehman.cuny.edu

Academic Editor: Ray Marks

Special Issue: Mobility and Aging: Falls Prevention Among the Elderly

OBM Geriatrics

2020, volume 4, issue 1

doi:10.21926/obm.geriatr.2001097
Received: October 03, 2019

Accepted: December 24, 2019

Published: January 03, 2020

\begin{abstract}
Falls have negative consequences for older adults, but falls can be reduced through interventions that target the reduction of fall risk factors. Cognitive behavioral education programs and therapeutic yoga are two interventions that have independently been used as a means to reduce the risk of falls. The purpose of this study was to determine if adding therapeutic yoga following an education intervention improved well known fall risk factors. Potential participants were recruited through a senior center for a 12-week fall prevention program that consisted of four weeks of an evidence-informed educational program and
\end{abstract}

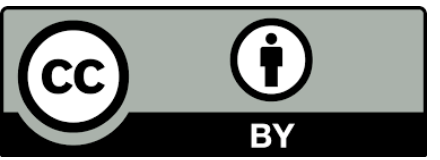

(C) 2020 by the author. This is an open access article distributed under the conditions of the Creative Commons by Attribution License, which permits unrestricted use, distribution, and reproduction in any medium or format, provided the original work is correctly cited. 
eight weeks of therapeutic yoga. Physical performance measures and psychosocial constructs were tested at baseline (T1), between the education intervention and yoga (T2), and after yoga (T3). Physical performance measures included the chair stand test to assess lower-body strength, the Timed Up-and-Go to assess agility and dynamic balance, and the Fullerton Advanced Balance Scale to assess static and dynamic balance. Psychosocial surveys included the University of Illinois at Chicago Fear of Falling to assess fear of falling, the Leisure Constraints Scale to assess constraints to physical activity, and the Activities Balance Confidence Scale, to assess perceived balance ability. A repeated measures test was used to determine if any significant changes in fall risk factors occurred. There were significant improvements in balance confidence after education, in agility and dynamic balance after yoga, and in fear of falling across the full 12-week intervention. Adding therapeutic yoga following education improved more outcomes than education alone and this combined intervention warrants further exploration as a fall risk reduction strategy.

\section{Keywords}

Fall risk reduction; rehabilitation therapy; yoga; education

\section{Introduction}

Falls are the leading cause of both fatal and nonfatal injuries for individuals over the age of 65 years [1]. Each year, more than $33 \%$ of older adults fall, and of those who fall $66 \%$ will have a repeated fall within six months [2]. Therefore, it is important to address fall risk factors in older adults.

Fall risk factors in older adults may be classified as intrinsic or extrinsic [3]. Intrinsic risk factors are considered to be within each individual and may include strength, and balance; or psychosocial factors (i.e., fear of falling (FoF), balance confidence, and perceived constraints to activity participation). Strength, particularly poor lower-body strength has been associated with higher rates of falls in older adults [4]. Balance is also an important and modifiable fall risk factor. Impaired balance has been demonstrated in $20-50 \%$ of older adults, and individuals with impaired balance have a three-fold increased risk of falls $[5,6]$. It is also imperative to address the psychosocial intrinsic fall risk factors, as they are important predictors of well-being. For example, FoF is prevalent in $20 \%$ to $60 \%$ of community-dwelling older adults $[7,8]$, is one of the most common consequences of a fall, and may even occur without a fall. FoF alone may lead to a reduced ability to complete activities of daily living and diminished participation in meaningful social and leisure activities [9]. Extrinsic risk factors are found within an individual's environment and include home hazards (i.e., clutter, broken stairs) or poorly maintained neighborhood structures (i.e., cracked sidewalks, poorly lit areas) [3].

Improvements in intrinsic and extrinsic fall risk factors are important in preventing future falls in older adults. Impairment in any of these areas may be common, especially in older adults who are frail [10]. Current guidelines for fall prevention suggest that a multifactorial approach targeting both intrinsic and extrinsic risk factors may be most effective for preventing falls in community- 
dwelling older adults. While balance and endurance training without education has improved physical performance, it has not been shown to be effective in reducing falls $[11,12]$.

Cognitive behavioral educational programs have been demonstrated to reduce extrinsic fall risk factors [13]. Common elements of educational programs include addressing extrinsic fall-related risk factors, unhelpful beliefs (intrinsic fall risk factors) regarding falls, how to discuss fall risks with healthcare providers, and education about simple low-impact exercises that can build strength [13, 14].

Therapeutic yoga has been suggested to rehabilitation therapists to assist their patients in improving intrinsic fall risk factors of strength, balance, FoF, and activity constraints [15]. Yoga consists of several combined elements, including physical postures (asanas), intentional breath control (pranayama), and meditation (dhyana). Research suggests that yoga leads to improvements in many intrinsic fall risk factors, including lower body strength, balance, FoF, balance confidence, and activity constraints in a variety of populations [15-25].

While education and yoga have individually demonstrated positive outcomes for fall risk reduction, combining the two interventions may have a greater impact on reducing fall risk factors than education only. A previous study combined an education intervention with Tai Chi and found significantly improved scores on a FoF measure and improved mobility in the combined group than either intervention alone [26]. Additionally, yoga has previously been combined with psychoeducational interventions for adults recovering from a stroke and the results indicated this approach was feasible and more beneficial than either intervention alone [27]. Therefore, the hypothesis that guided this study was that education followed by therapeutic yoga would have a greater impact on intrinsic fall risk factors than education alone for community-dwelling older adults.

\section{Materials and Methods}

Using a repeated measures design, this single arm study examined changes in select intrinsic fall risk factors among participants enrolled in a 12-week intervention, with measures taken at pre-education ( $T 1$, baseline), post-education ( $T 2$, four weeks), and post-yoga ( $T 3,12$ weeks).

The study sample consisted of older adults who resided in a rural, south-eastern county in the United States and the study occurred at a local senior center. To be eligible for the study, participants must have: been 65 or older and able to speak English, scored three or higher on the Mini-COG, and answered no to all questions on the Physical Activity Readiness Questionnaire (PAR-Q) or had physician approval (details on both measures in Data Collection). Potential participants were excluded if they were enrolled in hospice, were currently enrolled in another research study, or had unmanaged hypertension. Those who met inclusion/exclusion criteria were asked to complete all measures.

This research was approved by an IRB awarding institution on April 27, 2018 (Project identification code: Pro00074890).

\subsection{Intervention}

The 12-week intervention included eight bi-weekly sessions (four weeks) of the education program, and 16 bi-weekly sessions (eight weeks) of an evidence-based therapeutic yoga intervention led by either a certified yoga therapist (C-IAYT) or registered yoga teacher (RYT-500). 
The evidence informed educational classes were two-hour face-to-face sessions twice per week [13].

The therapeutic yoga sequence was originally developed by a yoga therapist to progressively challenge static and dynamic balance, and has previously demonstrated to be effective for improving balance in older adults [19]. Each 50-minute group-based yoga session contained the following components: a brief meditation (dhyana), breathwork (pranayama), and physical postures (asana). Each week the challenge level was increased either by introducing new postures, increasing repetitions, or holding postures for longer.

\subsection{Data Collection}

Demographic information collected included gender, race, marital status, and education level. At each data collection point participants reported the number of falls they had experienced in the past six months and identified their most recent fall. Two screeners were used to ensure minimal cognitive and physical ability to safely participate in the study. To assess changes in intrinsic fall risk factors, the physical performance measures included the Chair Stand Test, Timed Up and Go, and the Fullerton Advanced Balance Scale, and the psychosocial assessments included the University of Illinois Fear of Falling measure, Activity Specific Balance Confidence Scale, and the Leisure Constraints Scale.

\subsection{Screeners}

The Mini-COG was used as a screener for cognitive impairment in older adults, and participants who scored less than three were excluded due to the need for additional screening for cognitive impairments [28].

The PAR-Q is a screening tool commonly used before individuals begin engaging in regular physical activity [29]. If a participant answered 'yes' to one of the PAR-Q questions or presented with unmanaged high blood pressure, they were required to get physician consent to participate.

\subsection{Outcome Measures}

Three physical performance assessments evaluated lower body strength, agility and dynamic balance, and balance respectively. Three psychosocial measures assessed fall-related fears, balance confidence, and constraints associated with participation in physical activity.

\subsubsection{Chair Stand Test (CST)}

The CST assesses lower-body strength by having a participant repeatedly stand from a seated position for 30 seconds or until they are not able to stand in a full upright position [30]. Higher scores on the test suggest greater lower-body strength and indicate lower risk for falls [31].

\subsubsection{Timed Up and Go (TUG)}

The TUG assesses agility, and dynamic balance by timing how long it takes a participant to stand from a chair, walk three meters around a cone, and return to a seated position [30]. The 
score is recorded in seconds and a lower score indicates better agility and dynamic balance. Older adults who take $\geq 12$ seconds to complete the test are at increased risk of falling [32, 33].

\subsubsection{Fullerton Advanced Balance Scale (FAB)}

The FAB assesses static and dynamic balance [34]. Scores for each of the 10 tasks are summed and total scores range from 0-40 with a greater score being indicative of better balance and lower fall risk. Approximately $70 \%$ of older adults who score $<25$ are at higher risk for falls and need intervention [35].

\subsubsection{The University of Illinois at Chicago Fear of Falling Measure (UI-FoF)}

The UI-FoF was created to provide clinically meaningful descriptions of falling-related fears that older adults experience in daily living [36]. The UI-FoF measure has 16 items measured with a fouritem scale that ranges from one (very worried) to four (not at all worried); total can range from 1664 with lower scores indicating a greater FoF.

\subsubsection{Activities-Specific Balance Confidence Scale (ABC)}

The $A B C$ is a 16 -item instrument in which participants rate their confidence in their ability to perform various activities without losing balance or experiencing a sense of unsteadiness [9, 37]. Participants rate their confidence from $0 \%$ (no confidence) to $100 \%$ (complete confidence). Scores from each item are averaged to create a composite score ranging from 0-100 with a higher score indicating higher confidence.

\subsubsection{Leisure Constraint Scale (LCS)}

The LCS is a 21-item self-report survey that asks participants to indicate the extent to which each of the constraints hinder their participation in leisure activities [38]. Participants respond using a five-point Likert-type scale ranging from one (strongly agree) to five (strongly disagree). Total LCS scores range from one to 105 with higher scores indicating fewer constraints.

\subsection{Data Analysis}

Quantitative data were analyzed using IBM Statistical Package for Social Sciences (SPSS) v. 25 . Descriptive statistics were used to calculate the mean or frequency of demographic variables. Normality was assessed for each outcome measure using a Shapiro-Wilk test. Each measure, for at least one time point, had non-normally distributed data, so non-parametric tests were used for all measures. To determine differences between those who completed the full intervention and those who were lost to follow-up, Mann-Whitney $U$ tests were used for interval data (age, body mass index, and outcome measures).

Friedman's test determined changes in functional ability over time. If Friedman's test indicated significant differences between time points, post-hoc analyses with Wilcoxon signed-rank tests were conducted to determine which time points differed. A Bonferroni correction was applied based on the number of measures included in the post-hoc analysis $(p=.05 / 3)$ resulting in a 
significance level set at $p<0.017$. Percent change was calculated for each outcome measure between time periods (T1-T2/T1×100, T2-T3/T3 x100, and T1-T3/T1 x 100).

For each physical measure participants were dichotomized into high and low fall risk categories based on published clinical benchmarks adjusted for age and gender, and these were compared to national norms at each period. Participants' data were examined at each time period to see if clinically important changes occurred on these measures over time. Mann-Whitney $U$ tests were conducted to find significant differences between intervention completion and high-versus lowrisk baseline clinical status.

\section{Results}

A total of 23 participants enrolled in the study, 21 participants completed the education portion of the intervention (attended at least six out of eight (75\%) education sessions and completed T1 and $\mathrm{T} 2$ assessments), and of those 21 participants 13 participants continued to complete the yoga portion (attended both education and yoga 75\% of the time) and completed assessments at T3 in addition to those the assessments completed at $\mathrm{T} 1$ and T2). All participants were Caucasian with a mean age of $76 \pm 6.69$, (see Table 1 for group demographic information).

Scores from all three time points were compared using Friedman's repeated measures test. There were significant differences between scores for the TUG $(p=0.005)$, UI-FoF $(p=0.003)$, and ABC $(p<0.001)$ (see Table 2 for the repeated measures statistics). Post hoc analysis revealed: a significant difference between $\mathrm{T} 1$ and $\mathrm{T} 2$ (before and after education) for balance confidence as measured by the $A B C(p=0.001)$; a significant difference between T2 and T3 (before and after yoga) for dynamic balance as measured by the TUG $(p=0.012)$; and a significant difference on UI-FoF between T1 and T3 (see Table 3 for the post hoc statistics). According to the percent change calculation (see Table 4 for the percent change for each measure), improvements occurred for each measure between T1 and T2 except for the TUG and UI-FoF. From T2 to T3, there were improvements in the TUG, FAB, UI-FoF, and LCS. Overall, from T1 to T3, each measure improved, with the largest percent changes occurring in ABC, ACT, LCS, and UI-FoF. Overall, results support our hypothesis that the combination of the two programs will have a positive impact on improving functional fitness and balance confidence. 
Table 1 Demographic information between participants in the education intervention and in education and yoga.

\begin{tabular}{|c|c|c|}
\hline & Finished education only $(n=8)$ & $\begin{array}{l}\text { Finished education and yoga } \\
\qquad(n=13)\end{array}$ \\
\hline Age & $75.63 \pm 6.23$ & $76.00 \pm 6.69$ \\
\hline \multicolumn{3}{|l|}{ Gender } \\
\hline Female & $7(87.5 \%)$ & $12(92.3 \%)$ \\
\hline Male & $1(12.5 \%)$ & $1(7.69 \%)$ \\
\hline \multicolumn{3}{|l|}{ *Education } \\
\hline High school graduate & $4(50.00 \%)$ & $2(15.38 \%)$ \\
\hline Some college & $2(25.00 \%)$ & $2(15.38 \%)$ \\
\hline College graduate & $0(0.00 \%)$ & $1(7.69 \%)$ \\
\hline Some post-graduate & $1(12.5 \%)$ & $0(0.00 \%)$ \\
\hline Post-graduate degree & $1(12.5 \%)$ & $8(61.54 \%)$ \\
\hline \multicolumn{3}{|l|}{ Marital status } \\
\hline Married & $7(87.50 \%)$ & $\mathrm{C}$ \\
\hline Widowed & $0(0.00 \%)$ & $5(38.46 \%)$ \\
\hline Divorced & $1(12.50 \%)$ & $1(7.69 \%)$ \\
\hline Separated & $0(0.00 \%)$ & $1(7.69 \%)$ \\
\hline \multicolumn{3}{|l|}{ Self-rated health } \\
\hline Excellent & $1(12.50 \%)$ & $2(15.38 \%)$ \\
\hline Very good & $5(62.50 \%)$ & $9(69.23 \%)$ \\
\hline Fair & $2(25.00 \%)$ & $2(15.38 \%)$ \\
\hline Poor & $0(0.00 \%)$ & $0(0.00 \%)$ \\
\hline \multicolumn{3}{|l|}{ Employment status } \\
\hline Currently Work & $2(25.00 \%)$ & $2(25.00 \%)$ \\
\hline Retired & $6(75.00 \%)$ & $7(53.85 \%)$ \\
\hline \multicolumn{3}{|l|}{ External risk factors } \\
\hline Lives alone & $1(12.50 \%)$ & $6(46.15 \%)$ \\
\hline Activities are limited & $2(25.00 \%)$ & $5(38.46 \%)$ \\
\hline Stairs in home & $7(87.50 \%)$ & $9(69.23 \%)$ \\
\hline Fall in past month & $2(25.00 \%)$ & $2(15.38 \%)$ \\
\hline \multicolumn{3}{|l|}{ Clinical data } \\
\hline Systolic blood pressure & $127.50 \pm 11.50$ & $125.38 \pm 10.05$ \\
\hline Diastolic blood pressure & $76.50 \pm 11.14$ & $76.15 \pm 6.61$ \\
\hline Orthostatic hypotension & $0(0.00 \%)$ & $0(0.00 \%)$ \\
\hline Height & $64.26 \pm 2.68$ & $63.86 \pm 2.51$ \\
\hline Weight & $184.58 \pm 23.61$ & $180.09 \pm 42.68$ \\
\hline Body mass index & $31.38 \pm 2.98$ & $31.14 \pm 7.76$ \\
\hline
\end{tabular}

*Significantly different between groups at the .05 level using a Mann-Whitney $U$ test. 
Table 2 Psychosocial and Functional assessment mean scores across time in education and yoga participants.

\begin{tabular}{|c|c|c|c|c|}
\hline $\begin{array}{l}\text { Measure } \\
\text { (Construct) }\end{array}$ & $\begin{array}{l}\text { T1 Mean } \pm \text { SD } \\
(n=23)\end{array}$ & $\begin{array}{c}\text { T2 Mean } \pm \text { SD } \\
(n=21)\end{array}$ & $\begin{array}{l}\text { T3 Mean } \pm \text { SD } \\
(n=13)\end{array}$ & Chi square, (df) \\
\hline $\begin{array}{l}\text { Chair Stand Test (CST) } \\
\text { (Lower body strength) }\end{array}$ & $9.83 \pm 3.01$ & $11.08 \pm 3.20$ & $10.25 \pm 4.39$ & $\begin{array}{c}\chi^{2}=4.378(2) \\
p=.112\end{array}$ \\
\hline $\begin{array}{l}\text { *Timed Up and Go (TUG) } \\
\text { (Agility and dynamic balance) }\end{array}$ & $9.80 \pm 3.20$ & $10.43 \pm 3.16$ & $8.79 \pm 3.37$ & $\begin{array}{c}\chi^{2}=10.750(2) \\
p=.005\end{array}$ \\
\hline $\begin{array}{l}\text { Fullerton Advanced Balance } \\
\text { Scale (FAB) } \\
\text { (Static and dynamic balance) } \\
\text { *University of Illinois at }\end{array}$ & $28.50 \pm 6.17$ & $28.83 \pm 9.37$ & $29.17 \pm 7.48$ & $\begin{array}{c}\chi^{2}=.174(2) \\
p=.917\end{array}$ \\
\hline $\begin{array}{l}\text { Chicago Fear of Falling (UI- } \\
\text { FoF) } \\
\text { (Fear of falling) }\end{array}$ & $47.91 \pm 11.34$ & $47.27 \pm 19.09$ & $53.91 \pm 9.84$ & $\begin{array}{c}\chi^{2}=11.561(2) \\
p=.003\end{array}$ \\
\hline $\begin{array}{l}\text { *Activity Balance Confidence } \\
\text { Scale (ABC) } \\
\text { (Balance confidence) }\end{array}$ & $65.11 \pm 32.66$ & $90.03 \pm 27.48$ & $87.44 \pm 12.76$ & $\begin{array}{c}\chi^{2}=16.884(2) \\
p=.000\end{array}$ \\
\hline $\begin{array}{l}\text { Leisure Constraints Scale (LCS) } \\
\text { (constraints to physical } \\
\text { activity) }\end{array}$ & $35.55 \pm 10.95$ & $31.55 \pm 8.89$ & $30.45 \pm 9.89$ & $\begin{array}{c}\chi^{2}=3.951(2) \\
p=.139\end{array}$ \\
\hline
\end{tabular}

*significant at the $p<.05$ value using the Friedman's repeated measures test. $T 1=$ assessments at baseline, T2=assessments at four weeks between the end of the education intervention and the start of yoga. T3= assessments at 12 weeks after completion of both the education intervention and Yoga.

Table 3 Post hoc analysis with Wilcoxon's signed-rank test.

\begin{tabular}{lccc}
\hline \multicolumn{1}{c}{ Variable } & T1:T2 & T2:T3 & T1:T3 \\
\hline Timed Up and Go (TUG) & & & \\
(Agility and dynamic balance) & $Z=-1.817, p=.069$ & $* Z=-2.521$, & $* Z=-2.691$, \\
University of Illinois at Chicago Fear & & $p=.012$ & $p=.007$ \\
of Falling (UI-FoF) & $Z=-0.766, p=.444$ & $Z=-1.663, p=.096$ & $* Z=-2.805$, \\
(Fear of falling) & & & $p=.005$ \\
Activity Balance Confidence Scale & $* Z=-3.180$, & $Z=-.306, p=.760$ & $* Z=-3.065$, \\
(ABC) (Balance confidence) & $p=.001$ & $p=.002$ \\
\hline
\end{tabular}

*significant at the $\mathrm{p}<.017$ level using a post-hoc Bonferroni Correction. $\mathrm{T} 1=$ assessments at baseline, $\mathrm{T} 2=$ assessments at four weeks at the end of an education and before therapeutic yoga. T3= assessments at 12 weeks after both education and therapeutic yoga. 
Table 4 Percent change of psychosocial and functional assessments mean scores across three time points.

\begin{tabular}{|c|c|c|c|}
\hline Variable & T1:T2 & T2:T3 & T1:T3 \\
\hline $\begin{array}{l}\text { Chair Stand Test (CST) } \\
\text { (Lower body strength) }\end{array}$ & $+12.72 \%$ & $-7.49 \%$ & $+4.27 \%$ \\
\hline $\begin{array}{l}\text { Timed Up and Go } \\
\text { (TUG) } \\
\text { (Agility and dynamic } \\
\text { balance) }\end{array}$ & $-6.43 \%$ & $+15.72 \%$ & $+10.31 \%$ \\
\hline $\begin{array}{l}\text { Fullerton Advanced } \\
\text { Balance Scale (FAB) } \\
\text { (Static and dynamic } \\
\text { balance) }\end{array}$ & $+1.16 \%$ & $+1.18 \%$ & $+2.35 \%$ \\
\hline $\begin{array}{l}\text { University of Illinois at } \\
\text { Chicago Fear of Falling } \\
\text { (Ul-FoF) } \\
\text { (Fear of falling) }\end{array}$ & $-1.34 \%$ & $+12.31 \%$ & $+12.52 \%$ \\
\hline $\begin{array}{l}\text { Activity Balance } \\
\text { Confidence (ABC) } \\
\text { (Balance confidence) }\end{array}$ & $+38.27 \%$ & $-2.87 \%$ & $+34.30 \%$ \\
\hline $\begin{array}{l}\text { Leisure Constraints } \\
\text { Scale (LCS) } \\
\text { (constraints to } \\
\text { physical activity) }\end{array}$ & $+11.25 \%$ & $+3.49 \%$ & $+14.35 \%$ \\
\hline
\end{tabular}

+indicates improvement, -indicates decline, $\mathrm{T} 1=$ assessments at baseline, $\mathrm{T} 2=$ assessments at four weeks between education and yoga. T3= assessments at 12 weeks after both education and Yoga.

Additional analysis with Mann-Whitney $U$ tests were run with demographic information and baseline scores and revealed significant differences in marital status $(Z=-2.22, p=.026)$, living arrangement $(Z=-2.08, p=.037)$ and balance $(Z=-2.55, p=.011)$ between those who did and did not complete the intervention. The participants completing the full intervention were more commonly widowed and living alone than those who only completed education. Those who completed the full intervention had significantly better balance at baseline $(M=29.42 \pm 6.26)$ than those who did not complete the full intervention $(M=20.00 \pm 11.59)$. Tracking clinically important changes revealed improvement among some individuals and decline among others (see Table 5 for a description of the number of people who were clinically at risk based on physical performance scores).

Finally, clinically significant changes were tracked throughout both interventions. Overall 11 participants experienced a clinically significant change in fall risk factors with four of these changes occurring during the yoga portion (see Table 5). 
Table 5 Number of education and yoga participants at a higher risk of falls at each assessment time point.

\begin{tabular}{|c|c|c|c|c|c|c|}
\hline Measure & T1 & $\mathrm{T} 2$ & T3 & $\begin{array}{l}\text { \# people } \\
\text { T1:T2 } \\
(n=21)\end{array}$ & $\begin{array}{l}\text { \# people I } \\
\text { T2:T3 } \\
(n=12)\end{array}$ & $\begin{array}{l}\text { \# people } \\
\text { T1:T3 } \\
(n=12)\end{array}$ \\
\hline $\begin{array}{l}\text { Timed Up and } \\
\text { Go (Agility } \\
\text { and dynamic } \\
\text { balance) }\end{array}$ & $5 / 22$ & $5 / 21$ & $1 / 13$ & $\begin{array}{l}\text { Improved: } 4 \\
\text { No change: } 3 \\
\text { Decline: } 0\end{array}$ & $\begin{array}{l}\text { Improved: } 1 \\
\text { No change: } 1 \\
\text { Decline: } 0 \\
\text { Lost to follow- } \\
\text { up: } 4\end{array}$ & $\begin{array}{l}\text { Improved: } 1 \\
\text { No } \\
\text { changes: } 3 \\
\text { Decline: } 0 \\
\text { Lost to } \\
\text { follow-up: } 3\end{array}$ \\
\hline $\begin{array}{l}\text { Chair Stand } \\
\text { Test (Lower } \\
\text { body } \\
\text { strength) }\end{array}$ & $10 / 22$ & $7 / 21$ & $3 / 13$ & $\begin{array}{l}\text { Improved: } 3 \\
\text { No change: } 17 \\
\text { Declined: } 0\end{array}$ & $\begin{array}{l}\text { Improved: } 1 \\
\text { No change: } 8 \\
\text { Decline: } 0 \\
\text { Lost to follow- } \\
\text { up: } 9\end{array}$ & $\begin{array}{l}\text { Improved: } 1 \\
\text { No change: } \\
2 \\
\text { Decline: } 1 \\
\text { Lost to } \\
\text { follow-up: } 6\end{array}$ \\
\hline $\begin{array}{l}\text { Fullerton } \\
\text { Advanced } \\
\text { Balance Scale } \\
\text { (Static and } \\
\text { dynamic } \\
\text { balance) }\end{array}$ & $5 / 22$ & $9 / 21$ & $3 / 13$ & $\begin{array}{l}\text { Improved: } 0 \\
\text { No change: } 2 \\
\text { Declined: } 6 \\
\text { Lost to follow- } \\
\text { up: } 1\end{array}$ & $\begin{array}{l}\text { Improved: } 2 \\
\text { No change: } 2 \\
\text { Decline: } 0 \\
\text { Lost to follow- } \\
\text { up: } 5\end{array}$ & $\begin{array}{l}\text { Improved: } 0 \\
\text { No change: } \\
2 \\
\text { Decline: } 1 \\
\text { Lost to } \\
\text { follow-up: } 3\end{array}$ \\
\hline
\end{tabular}

$\mathrm{T} 1=$ baseline, $\mathrm{T} 2=$ =week 4 , between educational program and yoga, $\mathrm{T} 3=$ =week 12 after educational program and yoga were both complete.

\section{Discussion}

The purpose of this study was to evaluate if education followed by therapeutic yoga had a greater impact on intrinsic fall risk factors than education alone. There was a significant improvement in balance confidence (as measured by the $A B C$ ) before and after the education intervention, a significant improvement in agility and dynamic balance (as measured by the TUG) before and after the yoga intervention, and FoF (as measured by the UI-FOF) was improved only through combining education and yoga (between T1 and T3). The extension of the education program to include yoga provided greater improvements for study participants in agility, dynamic balance, and FoF.

These findings corroborate the findings of a meta-analysis by Chang et al. [39] who reported that multifactorial interventions reduced falls and risk of falls. While the present study did not track falls after the intervention was complete, the improvement of intrinsic fall risk factors support the findings by Chang et al [39]. These findings indicate that practitioners should consider using these two interventions to achieve a greater impact on the functional fitness and balance confidence of older adults. These study results also corroborate findings in a study by Schmid et al. 
who found that an intervention that merged yoga and a different fall prevention education led to better improvements in people with chronic stroke, than either yoga or education alone [27].

Results indicated that individuals who were widowed, lived alone and had better balance, were more likely to complete this study than individuals who were married or lived with others, or had lower balance. Results contradict the evidence reported by Murray et al. [40], who found that the absence of a partner was predictive of low engagement in lifestyle behavior change programs. However, Murray et al. also reported that individuals with high levels of social support were likely to engage in more exercise, thus, it is possible that the study participants experienced strong support from the group or from their membership at this senior center, potentially increasing their participation in the intervention.

Although not significant, participants experienced benefits in lower body strength, static balance, and constraints to physical activity. Notable is the clinically significant reduction in fall risk factors noted through both interventions (see Table 5). During the education intervention and yoga there were 11 participants who had a clinically significant improvement in functioning. Additionally, it seems perhaps yoga may have helped participants maintain balance; six participants digressed in balance throughout the education portion of the intervention, while participants were able to maintain balance during the yoga section of the study.

\section{Limitations}

As with any study, limitations exist. There was a high attrition rate, potentially due to the length of the intervention. Future research should explore if merging the interventions (rather than combining them sequentially) would help reduce attrition and produce greater changes in the clinical risks for falls. Additionally, it is difficult to tell how the high attrition rate may have impacted overall improvement, especially considering people with lower balance were less likely to complete the full intervention. Coe and colleagues [41] found that community-dwelling older adults were more likely to complete an education intervention than Tai Chi, likely due to the shorter intervention period of the education intervention. In a study that merged education and yoga for stroke survivors, Schmid et al provided 16 sessions over eight weeks and each session included both education and yoga. Merging the interventions may make both programs more accessible for study participants to complete [27]. This study did not utilize a control group as this was a preliminary study to explore if combining these two interventions sequentially yielded positive outcomes. It is possible that the increased attention the study participants received had an impact on the outcome measures and this should be explored in a larger study that uses an active control. Additionally, it is difficult to know if the benefits that occurred with yoga were specific to yoga or simply to a longer intervention. The sample size itself was too small to be fully representative for the elderly population, and results cannot be generalized. The yoga intervention implemented in this study was implemented at a very basic skill level. This may have been more beneficial for individuals who experience high levels of fear of falling or activity constraints, but less beneficial for individuals who have high levels of dynamic balance and low levels of fear of falling. Finally, more evidence is needed to determine if reducing fall risk factors translates to decreased rates of falls [16]. This type of nuance should be explored in greater detail in future studies. 


\section{Acknowledgments}

The authors would like to acknowledge Claire Kelly Allison for completing fidelity checklists at each session, and the community senior center for hosting the intervention, and all the participants who made this work possible. Additionally, the Clemson University Institute for Engaged Aging received the funding which supported this work and had previously established the organizational partnerships necessary for successful subject recruitment and provision of the site for the study.

\section{Author Contributions}

Em V. Adams: Contributed to study design, served as project manager for the study, implemented yoga intervention and assisted in the education intervention, assisted in data collection, completed the data analysis, wrote draft of methods and results, synthesized other contributions to the paper.

Marieke Van Puymbroeck: Contributed to study design, assisted in data collection, assisted in implementing the intervention, assisted in data analysis, reviewed several drafts of the paper, coauthored discussion.

Heather S. Torphy: Assisted in data collection, contributed to the introduction by writing a review of yoga and fall prevention, provided descriptions of measures, reviewed methods, assisted in the introduction by writing review of yoga research related to fall prevention.

Brian Helsel: Assisted in data collection, wrote descriptions for three outcome measures, contributed to the introduction by writing a review of fall risk factors, reviewed several drafts of the paper, and provided consultation on statistical analysis.

Karen A Kemper: Contributed to study design, assisted in data collection, reviewed several drafts of the manuscript, provided a description of clinical outcome measures, and provided a description of national norms.

Cheryl Dye: Contributed to study design, recruited participants, assisted in data collection, implemented the education intervention, and reviewed the manuscript.

Arlene A. Schmid: Contributed to study design, co-authored discussion, and reviewed several drafts of the manuscript.

\section{Funding}

This research was funding by a grant from the Pete and Sally Smith Family Foundation.

\section{Competing Interests}

The authors have declared that no competing interests exist.

\section{References}

1. Stevens JA, Corso PS, Finkelstein EA, Miller TR. The costs of fatal and non-fatal falls among older adults. Inj Prev. 2006; 12: 290-295.

2. Stevens JA, Mack KA, Paulozzi $\amalg$, Ballesteros MF. Self-reported falls and fall-related injuries among persons aged>or=65 Years-United States, 2006. J Safety Res. 2008; 39: 345-349. 
3. Chan WC, Law J, Seliske P. Bayesian spatial methods for small-area injury analysis: A study of geographical variation of falls in older people in the Wellington-Dufferin-Guelph health region of Ontario, Canada. Inj Prev. 2012; 18: 303-308.

4. Smee DJ, Anson JM, Waddington GS, Berry HL. Association between physical functionality and falls risk in community-living older adults. Curr Gerontol Geriatr Res. 2012; 2012: 864516.

5. Rubenstein LZ, Josephson KR. The epidemiology of falls and syncope. Clin Geriatr Med. 2002; 18: 141-158.

6. Rubenstein LZ, Josephson KR. Falls and their prevention in elderly people: What does the evidence show? Med Clin. 2006; 90: 807-824.

7. Murphy SL, Williams CS, Gill TM. Characteristics associated with fear of falling and activity restriction in community-living older persons. J Am Geriatr Soc. 2002; 50: 516-520.

8. Kempen GI, van Haastregt JC, McKee KJ, Delbaere K, Zijlstra GR. Socio-demographic, healthrelated and psychosocial correlates of fear of falling and avoidance of activity in communityliving older persons who avoid activity due to fear of falling. BMC Public Health. 2009; 9: 170.

9. Kumar A, Delbaere K, Zijlstra GA, Carpenter H, Iliffe S, Masud T, et al. Exercise for reducing fear of falling in older people living in the community: Cochrane systematic review and metaanalysis. Age Ageing. 2016; 45: 345-352.

10. Davis D, Rockwood M, Mitnitski AB. Impairments in mobility and balance in relation to frailty. Arch Gerontol. 2011; 53: 79-83.

11. Michalsen A, Grossman P, Acil A, Langhorst J, Lüdtke R, Esch T, et al. Rapid stress reduction and anxiolysis among distressed women as a consequence of a three-month intensive yoga program. Med Sci Monit. 2005; 11: CR555-CR561.

12. Freiberger E, Häberle L, Spirduso WW, Rixt Zijlstra GA. Long-term effects of three multicomponent exercise interventions on physical performance and fall-related psychological outcomes in community-dwelling older adults: A randomized controlled trial. J Am Geriatr Soc. 2012; 60: 437-446.

13. Tennstedt S, Howland J, Lachman M, Peterson E, Kasten L, Jette A. A randomized, controlled trial of a group intervention to reduce fear of falling and associated activity restriction in older adults. J Gerontol B Psychol Sci Soc Sci. 1998; 58: 384-392.

14. Clemson L, Cumming RG, Kendig H, Swann M, Heard R, Taylor K. The effectiveness of a community-based program for reducing the incidence of falls in the elderly: A randomized trial. J Am Geriatr Soc. 2004; 52: 1487-1494.

15. Schmid AA, van Puymbroeck $M$, Koceja DM. Effect of a 12-week yoga intervention on fear of falling and balance in older adults: A pilot study. Arch Phys Med Rehabil. 2010; 91: 576-583.

16. Youkhana $S$, Dean $C$, Wolff $M$, Sherrington $C$, Tiedemann A. Yoga-based exercise improves balance and mobility in people aged 60 and over: A systematic review and meta-analysis. Age Ageing. 2016; 45: 21-29.

17. Portz JD, Waddington E, Atler KE, Van Puymbroeck M. Schmid AA. Self-management and yoga for older adults with chronic stroke: A mixed-methods study of physical fitness and physical activity. Clin Gerontol. 2018; 41: 374-381.

18. Schmid AA, Van Puymbroeck M, Altenburger PA, Schalk NL, Dierks TA, Miller KK, et al. Poststroke balance improves with yoga: A pilot study. Stroke. 2012; 43: 2402-2407.

19. Van Puymbroeck M, Walter AA, Hawkins BL, Sharp JL, Woschkolup K, Urrea-Mendoza E, et al. Functional improvements in Parkinson's disease following a randomized trial of yoga. Evid 
Based Complement Alternat Med. 2018; 2018: 8516351.

20. Colgrove YS, Sharma N, Kludlng P, Potter D, Imming K, VandeHoef J, et al. Effect of yoga on motor function in people with Parkinson's disease: A randomized, controlled pilot sutdy. Yoga Phys Ther. 2012; 2: 2157-7595.

21. Schmid AA, Miller KK, Van Puymbroeck M, Schalk N. Feasibility and results of a case study of yoga to improve physical functioning in people with chronic traumatic brain injury. Disabil Rehabil. 2016; 38: 914-920.

22. Adams EV, Van Puymbroeck M, Walter A, Hawkins BL, Schmid AA, Sharpe JL. Predictors of functional improvements after therapeutic yoga intervention for people with Parkinson's disease. Int J Yoga Therap. 2019. doi:10.17761/2020-D-18-00005.

23. Adams EV, Crowe BM, Van Puymbroeck M, Kelly CT, Schmid AA. Yoga as a Community-based recreational therapy intervention for older adults: A pilot study. Therapeutic Recreation Journal. 2019; 53.

24. Walter AA, Adams EV, Van Puymbroeck M, Crowe BM, Urrea-Mendoza E, Hawkins BL, et al. Changes in nonmotor symptoms following an 8-week yoga intervention for people with Parkinson's disease. Int J Yoga Therap. 2019; 29: 91-99.

25. Danhauer SC, Addington EL, Cohen L, Sohl SJ, Van Puymbroeck M, Albinati NK, et al. Yoga for symptom management in oncology: A review of the evidence base and future directions for research. Cancer. 2019; 125: 1979-1989.

26. Huang TT, Yang LH, Liu CY. Reducing the fear of falling among community-dwelling elderly adults through cognitive-behavioural strategies and intense Tai Chi exercise: A randomized controlled trial. J Adv Nurs. 2011; 67: 961-971.

27. Schmid AA, Van Puymbroeck M, Portz JD, Atler KE, Fruhauf CA. Merging Yoga and Occupational Therapy (MY-OT): A feasibility and pilot study. Complement Ther Med. 2016; 28: 44-49.

28. Borson S, Scanlan J, Brush M, Vitaliano P, Dokmak A. The Mini-Cog: A cognitive vital signs measure for dementia screening in multi-lingual elderly. Int J Geriatr Psychiatry. 2000; 15: 1021-1027.

29. Reading T, Shephard R. Revision of the Physical Activity Readiness Questionnaire (PAR-Q). Can J Sport Sci. 1992; 17: 338-345.

30. Miotto JM, Chodzko-Zajko WJ, Reich JL, Supler MM. Reliability and validity of the Fullerton Functional Fitness Test: An independent replication study. J Aging Phys Act. 1999; 7: 339-353.

31. Rikli R, Jones J. Senior Fitness Test Manual. Champaign, IL: Human Kinetics Publishers, Inc; 2013.

32. Steffan TM, Hacker TA, Mollinger L. Age- and gender-related test performance in communitydwelling elderly people: Six-minute walk test, berg balance scale, timed up and go test, and gait speed. Phys Ther. 2002; 82: 128-136.

33. Rikli RE, Jones CJ. Functional fitness normative scores for community-residing older adults, ages 60-94. J Aging Phys Act. 1999; 7: 162-181.

34. Rose DJ, Lucchese N, Wiersma LD. Development of a multidimensional balance scale for use with functionally independent older adults. Arch Phys Med Rehabil. 2006; 87: 1478-1485.

35. Hernandez D, Rose DJ. Predicting which older adults will or will not fall using the Fullerton Advanced Balance Scale. Arch Phys Med Rehabil. 2008; 89: 2309-2315.

36. Velozo CA, Peterson EW. Developing meaningful fear of falling measures for community 
dwelling elderly. Am J Phys Med Rehabil. 2001; 80: 662-673.

37. Bloem BR, Hausdorff JM, Visser JE, Giladi N. Falls and freezing of gait in Parkinson's disease: A review of two interconnected, episodic phenomena. Mov Disord. 2004; 19: 871-884.

38. Van Puymbroeck M, Schmid A, Shinew K, Hsieh P. Influence of Hatha yoga on physical activity constraints, physical fitness, and body image of breast cancer survivors: A pilot study. Int J Yoga Therap. 2011; 21: 49-60.

39. Chang JT, Morton SC, Rubenstein LZ, Mojica WA, Maglione M, Suttorp MJ, et al. Interventions for the prevention of falls in older adults: Systematic review and meta-analysis of randomised clinical trials. BMJ Open. 2004; 328: 680.

40. Murray J, Craigs CL, Hill KM, Honey S, House A. A systematic review of patient reported factors associated with uptake and completion of cardiovascular lifestyle behaviour change. BMC Cardiovasc Disord. 2012; 12: 120.

41. Coe L, St John JA, Hariprasad S, Shankar KN, MacCulloch PA, Bettano AL, et al. An integrated approach to falls prevention: A model for linking clinical and community interventions through the massachusetts prevention and wellness trust fund. Front Public Heal. 2017; 5 : 38.

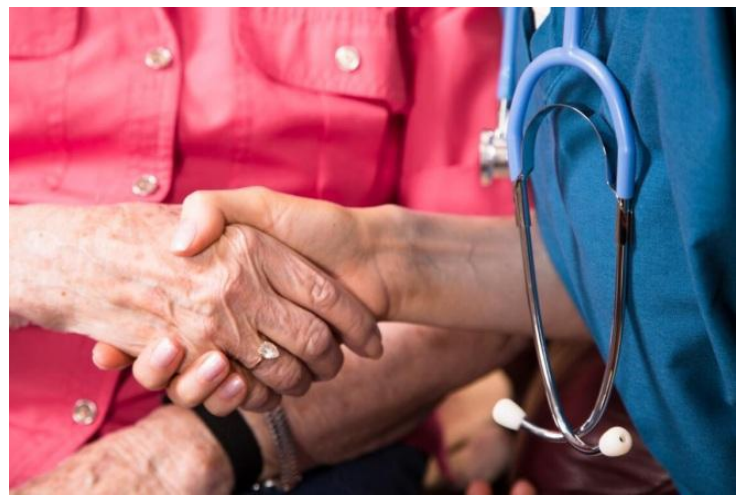

Enjoy OBM Geriatrics by:

1. Submitting a manuscript

2. Joining in volunteer reviewer bank

3. Joining Editorial Board

4. Guest editing a special issue

For more details, please visit: http://www.lidsen.com/journals/geriatrics 